\title{
DIFFERENT APPROACHES IN DETERMINING THE VERTICAL AND HORIZONTAL JAW RELATIONS DURING COMPLETE DENTURE FABRICATION - A LITERATURE REVIEW
}

\author{
Maria Zielke, Joanna Jasnoch, Izabela Maciejewska \\ Department of Dental Prosthodontics, Medical University of Gdansk, Poland
}

\begin{abstract}
Recording the jaw relations is a critical step during the fabrication of complete dentures. Both vertical and horizontal relations must be correctly established to ensure efficient function of the complete dentures with the least amount of trauma to the supporting tissues and temporomandibular joints (TMJs). The aim of this review was to collect comprehensive data about the most recommended methods for determining the optimal vertical dimension of occlusion (VDO) during the fabrication of complete dentures and to determine whether and/or to what extent these methods respect the correct spatial relations in TMJs. An electronic search through the PubMed, Web of Science, OVID, SCOPUS and EBSCO search engines selected 111 references from peer-reviewed journals, which met the inclusion criteria for this literature review. The single, exclusive and scientifically confirmed consensus for the determination of both the VDO and centric relation during complete denture fabrication is still lacking. Authors agree that the establishment of an incorrect relation between the maxilla and mandible causes severe, mostly harmful consequences in the stomatognathic system. So far the available procedures are associated with a high degree of subjective clinical judgements and variability. Thus, ongoing studies with the application of new technologies are still current and strongly recommended.
\end{abstract}

KEY WORDS: complete denture, vertical dimension, TMJ, centric relation.

J Stoma 2021; 74, 3: 195-202

DOI: https://doi.org/10.5114/jos.2021.108874

\section{INTRODUCTION}

A critical step during complete edentulism treatment is the restoration of the vertical dimension of occlusion (VDO), which should come in concert with defining the appropriate centric relation (CR) [1-7]. Failures during this clinical step might not only compromise the facial appearance but also lead to faster loss of the prosthetic landmark and initiate masticatory muscle discomfort and/or tiredness with subsequent insufficient mastication [3, 4, 7-12]. Prolonged functioning with the incorrectly defined VDO might result in tempo- romandibular joint (TMJ) disorder as a direct effect of trauma resulting from the inappropriate position and movement of condyles $[2,4,11]$.

Besides aesthetic results following from the appropriate replacement of missing teeth and associated tissue of the resorbed craniofacial landmark, the complete dentures should be comfortable in use. Both factors depend on the restoration of the ideal or at least earlier adopted, but correct VDO. Thus, a prerequisite is to define what constitutes the "ideal occlusion" with the understanding that the VDO is not rigid and unchangeable during the patient's lifetime $[4,13]$. The concept of occlusion in
JOURNAL OF STOMATOLOGY CZASOPISMO STOMATOLOGICZNE
AdDRESS FOR CORRESPONDENCE: Izabela Maciejewska, DMD, PhD, Department of Dental Prosthodontics, Medical University of Gdańsk, 18 Orzeszkowej St., 80-208 Gdańsk, Poland, phone: +48 5834916 85, fax: +48 5834915 66, e-mail: izabela.maciejewska@gumed.edu.pl

ReCEIVED: 12.03.2021 • ACCEPTED: 11.05.2021 • Published: 30.08.2021 
the production of complete dentures has been thoroughly investigated and proposed as either balanced or nonbalanced (flat). The former assumes the reconstruction of both the occlusal and articular mandible movements as well as artificial teeth contacts that imitate the natural dentition [14]. Thus, the balanced occlusion includes the condylar path, incisal and canine guidance and compensating curves pathway. To achieve these goals the usage of a semi- or fully-adjustable articulator is necessary $[4,15]$. On the other hand, a non-balanced occlusion includes Spee's and Wilson's curves pathway but by providing the protrusive contacts on posterior teeth, it eliminates the role of the condylar slope and Christensen's phenomenon. Hence, the plane of occlusion remains completely flat and the artificial teeth interact at both centric and eccentric occlusion [14]. This second technique is commonly used in clinical practices and laboratories because of its simplicity, although it compromises the relations in TMJs. Regardless of the method used for complete denture fabrication, the critical step is the optimal establishment of the VDO.

Since there is a lack of consent in the topic of registration of both vertical and horizontal jaw relations during complete denture fabrication, the aim of this review was to examine the widest available range of literature, to facilitate clinicians choosing the method of establishing the VDO/CR and assemble former peer reviewed findings. The specific goal was to cover an extensive scope of literature that depicts the two-stage procedure (VDO and CR registration), which seems critical for the long term well-being of edentulous patients as well as to determine whether and/or to what extent these methods respect the spatial relations in TMJs. There is a vast amount of literature on establishing the proper intermaxillary relations, but only a minority simultaneously consider both the vertical and horizontal component of occlusion.

\section{MATERIAL AND METHODS}

An electronic search through the PubMed, SCOPUS, EBSCO, Web of Science and OVID search engines was carried out using a conjunction of MeSH terms. Firstly, the phrase "complete denture" was used, which gave 14524 results in PubMed, 15376 in SCOPUS, 17777 in EBSCO, 4885 in Web of Science and 3523 in OVID. Secondly, the next key phrase "occlusal vertical dimension" limited the findings to 854 results from PubMed, 266 from SCOPUS, 208 from EBSCO, 95 from Web of Science and 59 from OVID. The "Centric relation" phrase resulted in 122 findings from PubMed, 53 from SCOPUS, 22 from EBSCO, 14 from Web of Science and 16 from OVID. Then word "occlusion" limited the findings as follows: 118 articles in PubMed, 47 in SCOPUS, 8 in EBSCO, 6 in Web of Science and 8 in OVID. Afterwards, the excluding terms were added. The phrase "Partial dentures" limited records to 103 cases in PubMed, 37 in SCOPUS, 8 in EBSCO, 6 in Web of Science and 7 in OVID. "Dental implants" excluded the next papers and resulted in the positive search of 90 results in PubMed, 32 in SCOPUS, 6 in EBSCO, 6 in Web of Science and 5 in OVID, while the phrase "fixed restorations" resulted in 89 papers from PubMed and 31 from SCOPUS. The last phrase of exclusion did not make any changes in the rest of the investigated databases. After limiting searched articles exclusively to English, the authors selected 75 records from PubMed, 31 from SCOPUS, 6 from EBSCO, 5 from Web of Science and 5 from OVID (Table 1). Records which were duplicated among these databases were removed. A further manual search through the paper print resources of the library of the Medical University of Gdansk was carried out, which provided the authors with another 11 manuscripts.

TABLE 1. The process of collection of records carried out in five databases with key words for inclusion and exclusion $(\mathrm{MeSH})$

\begin{tabular}{|c|c|c|c|c|c|}
\hline & PubMed & SCOPUS & EBSCO & Web of Science & OVID \\
\hline Complete dentures & 14524 & 15376 & 17777 & 4885 & 3523 \\
\hline \multicolumn{6}{|l|}{ AND } \\
\hline Occlusal vertical dimension & 854 & 266 & 208 & 95 & 59 \\
\hline Centric relation & 122 & 53 & 22 & 14 & 16 \\
\hline Occlusion & 118 & 47 & 8 & 6 & 8 \\
\hline \multicolumn{6}{|l|}{ NOT } \\
\hline Partial dentures & 103 & 37 & 8 & 6 & 7 \\
\hline Dental implants & 90 & 32 & 6 & 6 & 5 \\
\hline Fixed restorations & 89 & 31 & 6 & 6 & 5 \\
\hline \multicolumn{6}{|l|}{ Language } \\
\hline English & 75 & 31 & 6 & 5 & 5 \\
\hline
\end{tabular}




\section{RESULTS}

111 references were accepted as useful for approaching the goal of this manuscript (Table 2).

\section{DISCUSSION}

There are several maneuvers used by clinicians to reconstruct the ideal mandible to maxilla relation during the creation of complete prostheses. Some are used more often than others, and even though there are millions of edentulous patients treated yearly worldwide, a single optimal method for determining the VDO is still missing. According to the opinion of clinically experienced prosthodontists the combination of two or three methods is mostly recommended [4, 7, 16-18]. This should allow for validation of the collected data and application of an appropriate adjustment if needed.

\section{VERTICAL DIMENSION AT REST}

The most popular and highly recommended clinical procedure in treating edentulism is taking advantage of the vertical dimension at rest (VDR). According to the Glossary of Prosthodontic Terms, VDR is a postural position of the mandible when an individual is resting comfortably in an upright position and the associated muscles are in a state of minimal contractual activity [19]. Such a popular application of the VDR during the VDO determination comes from the results of research which led to the conclusion that the mandible rest position is a kind of "dental fingerprint" and remains stable throughout the lifetime [9, 20-23]. Multiple researchers indicated an average of 2 to $4 \mathrm{~mm}$ free interocclusal space between the mandible and maxilla at the rest position, concluding that this free space should be subtracted from the dimension of the VDR to establish the appropriate VDO [1-4, 21, 24-26]. Some authors stated that the major corrections of these proposed dimensions seemed reasonable for facial aesthetics improvement $[2,4,24]$. For the measurement of VDR two reference skin points in the midface must be marked. Usually, they are located at the bottom of the nose ( $\mathrm{Sn}$ - subnasale) and on the top of the chin (Gn - gnathion) $[4,9,16,18,21,27-29]$, but some authors recommend the tip of the nose ( $\mathrm{Tn}$ ) rather than $\mathrm{Sn}$ because in their opinion it was less movable [30-34]. Others suggested that, using special devices that measure the distance between the skin points on the forehead and chin would give more precise and repeatable results $[35,36]$. All those authors consent on one point, that for measuring the VDR accurately it is crucial to keep the patient's head firm with the Frankfort plane parallel to the floor, the lower jaw relaxed and lips just touching. The fulfilment of all these prerequisites should grant the harmonic tonus of the masticatory muscles $[4,16,21,28,37-41]$
TABLE 2. Final results concluding the searched records

\begin{tabular}{|l|c|c|c|}
\hline & $\begin{array}{c}\text { Manuscripts } \\
\text { included }\end{array}$ & $\begin{array}{c}\text { Duplicates } \\
\text { between } \\
\text { databases }\end{array}$ & $\begin{array}{c}\text { Final } \\
\text { result from } \\
\text { particular } \\
\text { databases }\end{array}$ \\
\hline PubMed & 75 & 0 & 75 \\
\hline SCOPUS & 31 & 10 & 21 \\
\hline EBSCO & 6 & 2 & 4 \\
\hline Web of Science & 5 & 5 & 0 \\
\hline OVID & 5 & 5 & 0 \\
\hline Manual search & 11 & 0 & 11 \\
\hline Total & 133 & 22 & 111 \\
\hline
\end{tabular}

with their minimal activity to counteract gravity and to create a negative intraoral pressure [12]. In contrast, Wright denied the crucial role of patient's posture for accurate recording of the VDO, emphasizing instead the role of the patient's comfort [42].

The continuing investigations revealed that the VDR changes continuously with ageing and tooth loss $[3,4$, 43-50]; thus, sole measurement of the distance between two selected points is not an entirely reliable method of VDO assessment, especially in edentulous patients [48, 51-53]. Swerdlow indicated that an interocclusal distance accommodates to changes in the vertical dimension of occlusion [54]. Additionally, Atwood proved that sequential results of VDR height are rarely constant, even in a single patient [55]. Others' main claim referred to the mobility of the skin reference points [3, 30-34, 56, 57]. Some authors observed a discrepancy in movement extent between the skin and skeletal reference points, indicating that the distance between bone landmark points is longer than that measured between the skin reference points [3, 33, 34]. Gross et al. explained this phenomenon as a result of compensation of facial soft tissue for changes of muscle tonus [33]. Consequently, measurements obtained from the skin reference points may differ even twofold from those measured on the skeletal landmark, subsequently leading to errors in VDO determination [34]. Further controversies about the reliability of the VDR/VDO method came from studies which showed that the postural vertical height is a range rather than one rigid position and depends on head position, time of day of recording, and presence or absence of dentures in the mouth [13,28,58-61]. Also, the muscle tonus reflects current tiredness, anxiety or fear, pain, and parafunctional habits or diseases of the mandibular neuro-masculatory complex $[4,18,28,37,53,59,62-64]$.

\section{PRONUNCIATION METHODS}

Since there was no consensus on accepting the VDR method as reliable enough for accurate assessment of the VDO in edentulism, clinicians searched for an- 
other procedure which would complement the VDR in gathering data for the optimal VDO assessment. The one, firstly described by Silvermann [65], showed that during pronunciation of the sibilant sounds $(/ \mathrm{s} /, / \mathrm{sh} /, / \mathrm{ch} /)$ the incisal edges of anterior teeth localize at the least separation and closest speaking space (CSS). The CSS ranges from 0 to $10 \mathrm{~mm}$ with the average of $2 \mathrm{~mm}$ [65-67]. According to Silvermann, the CSS remains stable throughout the lifetime and should be recorded before the loss of teeth [65]. Two other enthusiasts of the CSS method, Pound and Murrell, claimed that the CSS allows one not only to determine the appropriate VDO, but also to find the CR and correct position of the upper incisors and canines [68,69]. A similar phonetic method including the vowels "O" and " $E$ " was proposed by Marko et al., who defined the average interocclusal space during pronunciation of the vowels "O" and " $E$ " as $5.5 \mathrm{~mm}$ and $7.5 \mathrm{~mm}$, respectively [17]. Negucioiu et al. though, preferably used the vowels "S" and "I" to prevent overestimating the VDO [70]. Although all supporters of the pronunciation method emphasize its advantages, they also claim that the CSS depends on the localization of the /s/ sound in a particular word or phrase. It also differs among individuals and depends on the presence or absence of the occlusion rims in the mouth, and thus cannot be used as an exclusive method for VDO recording $[67,71,72]$.

\section{SWALLOWING}

The physiological concept of establishing inter-jaw relation benefits from the swallowing phenomenon. Shanahan described that swallowing starts from the maximum intercuspation and thereafter the mandible returns to the postural rest position. The author suggested that swallowing allows for recording both the VDO and CR $[26,73]$. However, Millet et al. and Cimic et al. disagreed with this suggestion and emphasized that swallowing can only be justified when setting the vertical position of mandible but should not be used to assess the CR $[38,74]$. Similarly, Abdel-Hakim proved that the mandible position during swallowing differs from its CR position, and thus the validity of swallowing method is questionable [75]. Ismail and George, even though they observed an increase in height of the prosthetically rehabilitated face compared to the pre-extraction data, still recommended swallowing in edentulous patients as a reliable method, but only for VDO determination [76].

\section{LATERAL CEPHALOGRAMS}

The evaluation of lateral cephalograms has been widely described as a predictable tool for establishing the correct VDO [13, 58, 77-80]. Generally, there are two known approaches that benefit from this method. The first follows the localization of specific points marked on a skeletal landmark. It compares the total face height measured between the nasion and gnathion, the upper face height measured from the nasion to the anterior nasal spine (ANS), and the lower face height, which is the span between the ANS and the gnathion. According to this theory, when the mandible remains at the rest position, the ratio between the upper and lower face height is approximately $43 \%$ to $57 \%$, which stands for the appropriate vertical dimension [79, 81]. Hull et al. postulated to take at least three trials and assured that as long as at least two out of three results correspond within $1 \mathrm{~mm}$, it ascertains the measurement accuracy [81]. In contrast, Ismail's et al. evaluation showed that while treating edentulism, the VDO values obtained from the lateral encephalogram analyses were mostly too high, but "self-adjusted" during the first six months of complete denture wearing [51]. Moreover, some authors claim that while formulating equations for correct calculation of data obtained from the lateral cephalogram analyses only a limited and specific population was evaluated, which may compromise drawing general conclusions and applying them to the worldwide population $[13,77]$.

The second approach to establish the VDO with the lateral cephalogram analysis is based on a comparison of the angle crossed between the line drawn from the Xi (placed in the center of the mandibular ascending ramus and the Frankfort plane) and ANS points and the line bridging the ANS and suprapogonion (Pm) points $[58,79]$. The obtained values are later compared to orthodontic norms. The results of Brzoza et al. obtained from edentulous patients were almost equal $\left(47,6^{\circ}\right)$ to the orthodontic norm $\left(47 \pm 4^{\circ}\right)$, which resulted in these and other authors' opinion that the cephalometric analysis is a manageable, effortless, economical and atraumatic way for the precise estimation and control of the reconstructed VDO during the fabrication of complete dentures [13, 79]. However, Brzoza et al. emphasized that their study was conducted with patients who had just become edentulous, which might have influenced the final result [79]. The caution during the lateral cephalograms evaluation in the edentulous population was accentuated by Enkling et al. [82]. The authors stressed the fact that cephalometric norms applied in orthodontics are established in the dentate population and exclude the progressive facial growth [82]. Considering these doubts, some authors suggested using lateral cephalograms as a pre-extraction record, which will be helpful after the loss of dentition $[81,83]$.

\section{PRE-EXTRACTION RECORDS}

Uncertainty and problems with the correct VDO reconstruction in edentulous patients became an incentive to collect the pre-extraction records, which could direct the precise reconstruction of the VDO in both 
the partially edentulous but specifically in the totally edentulous patients. Some authors recommended using a specific tool called a dakometer, which simultaneously records the distance between the nose and chin in the MI position and location of incisal edges of the upper central incisors $[24,63]$. Turrell depicted this procedure as much more accurate than numerous others used after tooth extraction [24]. Comparable to the dakometer is the Sorenson Profile Scale, which Smith described as "surprisingly reliable", although it requires one to label the reference points on the skin, which might result in their movement or smearing $[2,84]$. Due to the fact that such tools are hardly available nowadays, other authors proposed fabricating face profile templates made of wire and adjusted to the facial contour [85]. Others suggested tracing the face profile on the pantograph and cutting them out suitably from cardboard [24, 86]. Collecting the pre-extraction records seems very helpful during the reconstruction of facial aesthetics while fabricating the complete denture, but it is very unlikely to collect the life-lasting data for every individual just in case of teeth loss. This idea also raises the question whether to collect the sequential data or the single one and, if so, what age would be the most representative.

\section{ADDITIONAL METHODS}

Another tool dedicated to the accurate determination of the VDO is the bimeter by Boss $[1,24,25]$. The bimeter was designed for the measurement of biting forces due to the author's presumption that the greatest biting power occurs when a mandible movement starts from its rest position [1]. Consequently, the appropriate VDO should be diminished by $3 \mathrm{~mm}$ from the mandible position recorded at the largest stretch of the mastication muscles. This research was questioned by Boucher et al., who concluded that the measurement of the VDO with the bimeter is strongly subjective [8].

The next method, which relies on the patient's neuromuscular perception, is the screw-jack method [87, 88]. It suggests that every individual is able to judge the comfort of the VDO even if all teeth have been lost. This ability results from a tactile sense. However, numerous neural diseases, e.g. Parkinson's disease, exclude this method. There are also opinions that the presence of the screwjack in the mouth can alter the patient's perception [18]. Some authors followed the patient's feedback while using the central bearing device from an intraoral Gothic arch but still suggested carefully ascertaining established values on the wax trial denture with the phonetics and aesthetic appearance of a patient $[7,89]$.

A limited number of authors stated that measurement of existing dentures might provide the correct VDO [90]. They either compare the left eye-ear distance to predict the chin-nose distance $[78,91]$ or use the "open rest position" (a position with minimal lip separation) to de- termine the VDO [92]. Pitigoi-Aron et al. recommended establishing the interalveolar dimension by copying the old dentures' dimension with a caliper device, which is a modified Boley gauge. In this study, the recorded dimension becomes a permanent reference point for a patient, which is usable during adjustment of wax rims and includes the loss of the occlusal vertical dimension (OVD) after denture fabrication [93]. Furthermore, a study was conducted to evaluate the average interalveolar distance in the edentate population, which revealed that the distance between the maxillary vestibular folds and the mesiobuccal tubercle for the first molar and premolar was approximately $17.25 \mathrm{~mm}$ and $20.11 \mathrm{~mm}$, respectively [94].

Other anthropometric approaches for finding the correlation between VDO and finger length were used independently by Bhandari's and Sihuay-Torres's teams $[29,95,96]$. Bhandari et al. suggested that the little finger length almost equals the VDO, but although SihuayTorres et al. found a correlation between the index, middle and little finger and the VDO, they still recommended the method as a supplementary one [95, 96]. Since no ongoing research has confirmed the scientific value and reliability of these methods, they should be performed cautiously or confirmed with the corresponding methods.

\section{CENTRIC RELATION REGISTRATION}

Once the VDO is recorded, the central relation must be established. The CR is a physiological position of condyles, which are centered in the fossa in their most superior and anterior position with an appropriate location to the disc and a correct relation to the posterior part of the articular eminence [19]. CR is a gnathological concept and does not depend on contact with the teeth. It is unique for each individual [2].

\section{GOTHIC ARCH AND ARROWHEAD}

Drawing the Gothic arch is one of the most popular techniques, widely described in the literature as repeatable, accurate and easily applied even by inexperienced clinicians $[7,89,97]$. The idea of the Gothic arch comes from the registration of the extreme forward, backward and side movements of the mandible. With the rod mounted on the upper dental arch between first molars and the recording plate mounted on the lower dental arch, a patient draws a figure which resembles a Gothic arch and an arrowhead [7, 89]. The central line that crosses the arch covers the centric relation, maximum intercuspation (MI; central occlusion) and maximum protrusion points. Authors differ in their opinions about the localization of the MI spot $[1,4,7,37,89,98]$. Some of them advocated the arrowhead $[4,7,89,98]$, while others suggested that the MI is located 0.5 to $1.5 \mathrm{~mm}$ anteriorly from the arrowhead $[1,37]$. The latter opinion 
includes the fact that only $10 \%$ of the global population shows the coincidence of localization of the CR and MI, while approximately $90 \%$ of the population shows the up to $1.5 \mathrm{~mm}$ anterior slip called "freedom in centric" [37]. Ismail and Rokni recommended the reconstruction of the mandible-maxilla relation with the detailed assessment of the CR including the freedom in centric, which, in the authors' opinion, would prevent trauma of the TMJs [99]. Some authors point out the limits of the Gothic arch method as it is more prone to errors due to muscle tiredness or mishandling of the device [100-102]. They also state that it may be inaccurate among patients with Angle's class II or III or patients with dementia and disturbed muscle coordination [101]. Moreover, a hypertrophic tongue, which is often present in edentulous patients, can cause a displacement of the recording tools. Yurksta and Kapur's study showed that the position and inclination of the central bearing rod as well as the force which a patient applies when closing the mouth have a great influence on the results of this method [100]. Myers et al. suggested that the Gothic arch tracing reproduces the CR equally to the method that implements the dentist's assistance, which in assumption resembles Dawson's grasp [103].

The contemporary approach to obtain the Gothic arch tracing is the use of an electronic face-bow, such as the ARCUS digma II (KaVo Dental GmbH, Biberach, Germany). Following the condylar guidance with ultrasonic signaling the system records the 3D (protrusive, retrusive and lateral) mandibular movements, concurrently calculating and mapping the movements of junctions, which eventually allows for direction of the mandible to the exact CR position. Additionally, the EMG channel allows for the simultaneous measurement of muscle tonus [104]. On the other hand, the present authors' observations showed that the size and weight of the face-bow can jeopardize the patient's muscle coordination. Moreover, such equipment is not commonly available in dental practices.

Closing the mouth with a dentist's thumb pushing (guiding) the chin backwards is a worldwide practiced procedure for setting the most distal mandible position $[27,105,106]$. Its performance does not require any special equipment apart from wax rims. Importantly, it is also fast and relatively easy, which elderly patients specifically appreciate. This procedure seems the most beneficial for patients wearing complete dentures which are very old, with decreased VDO or those who tend to protrude the mandible [106-108]. All authors agree that the dentist's manual guidance should be done carefully, because exceeding the most distal position may result in a TMJ disorder accompanied by pain or tinnitus [27, 105108]. Instructing a patient to touch the posterior border of the upper baseplate with the tip of the tongue can also help to direct the mandible to the maximum distal position and might be used separately [101, 106, 109-111]. Boyanov modified this method by closing the mouth with the head leaning backwards [5]. The author explained that his modification provided a reflex shortening of the suprahyoid muscles, which consequently pulled the mandible downwards and by acting in concert with the temporal muscles during mouth closing, directed the mandible into the CR position [5]. The authors of this manuscript are currently running the project, which includes bilateral cone beam computed tomography (CBCT) evaluation of TMJs after establishment of the OVD and CR. The CBCT scans are taken with the wax rims fixed in the patient's mouth. This allows for immediate modification of the maxilla to mandible relation, if necessary, and preliminary conclusions are very promising.

\section{CONCLUSIONS}

There is a lack of a single and exclusive, scientifically confirmed consensus for the determination of both the VDO and CR during complete denture fabrication. All authors agree that the establishment of the incorrect relation between the maxilla and mandible causes severe problems in the stomatognathic system. So far the available procedures are associated with a high degree of subjective clinical judgement and variability. Thus, ongoing studies with the application of new technologies are still valid and strongly recommended.

\section{CONFLICT OF INTEREST}

The authors declare no potential conflicts of interest with respect to the research, authorship, and/or publication of this article.

\section{References}

1. Boos RH. Intermaxillary relation established by biting power. J Am Dent Assoc 1940; 27: 1192-1199.

2. Willie RG. Trends in clinical methods of establishing an ideal interarch relationship. J Prosthet Dent 1958; 8: 243-251.

3. Nairn RI. Interrelated factors in complete denture construction. J Prosthet Dent 1965; 15: 19-24.

4. McCord JF, Grant AA. Registration: Stage II - intermaxillary relations. Br Dent J 2000; 188: 601-606.

5. Boyanov B. Determining vertical dimension of occlusion and centric relation. J Prosthet Dent 1970; 24: 18-24.

6. Pyott JE, Schaeffer A. Centric relation and vertical dimension by cephalometric roentgenograms. J Prosthet Dent 1954; 4: 35-41.

7. Rubel B, Hill EE. Intraoral gothic arch tracing. N Y State Dent J 2011; 77: $40-43$

8. Boucher LJ, Zwemer TJ, Pflughoeft F. Can biting force be used as a criterion for registering vertical dimension? J Prosthet Dent 1959; 9: 594-599.

9. McGee GF. Use of facial measurements in deter-mining vertical dimension. J Am Dent Assoc 1947; 35: 342-350.

10. Abdullah ZS, Rahman HA. Occlusal vertical dimension and its correlation with lingual frenum. M Dent J 2007; 4: 188-191.

11. McCord JF, Grant AA. Identification of complete denture problems: a summary. Br Dent J 2000; 189: 128-134.

12. Bakke M. Mandibular elevator muscles: physiology, action, and effect of dental occlusion. Scand J Dent Res 1993; 101: 314-331. 
13. Strajnic L, Stanisic-Sinobad D, Markovic D, Stojanović L. Cephalometric indicators of the vertical dimension of occlusion. Coll Antropol 2008; 32: 535-541.

14. Abduo J. Occlusal schemes for complete dentures: a systematic review. Int J Prosthodont 2013; 26: 26-33.

15. Tanaka H. The Teledyne Articulator System 154 as applied to complete denture construction. Dent Clin North Am 1979; 23 289-303.

16. Toolson LB, Smith DE. Clinical measurement and evaluation of vertical dimension. J Prosthet Dent 1982; 47: 236-241.

17. Marko I, Nebojša K, Ljiljana A, et al. Determination of vertical dimension of occlusion by using the phonetic vowel "O" and " $E$ ". Vojnosanit Pregl 2015; 72: 123-131.

18. Alhajj MN, Khalifa N, Abduo J, Amran AG, Ismail IA. Determination of occlusal vertical dimension for complete dentures patients: an updated review. J Oral Rehabil 2017; 44: 896-907.

19. The glossary of prosthodontic terms: ninth edition. J Prosthet Dent 2017; 117 (5S): el-e105.

20. Potgieter PJ, Monteith BD, Kemp PL. The determination of freeway space in edentulous patients: a cephalometric approach. J Oral Rehabil 1983; 10: 283-293.

21. Pleasure MA. Correct vertical dimension and freeway space. J Am Dent Assoc 1951; 43: 160-163.

22. Hickey JC, Williams BH, Woelfel JB. Stability of mandibular rest position. J Prosthet Dent 1961; 11: 566-572.

23. Thompson JR, Brodie AG. Factors in the position of the mandible. J Am Dent Assoc 1942; 29: 925-941.

24. Turrell AJ. Clinical assessment of vertical dimension. J Prosthet Dent 1972; 28: 238-246.

25. Fayz F, Eslami A. Determination of occlusal vertical dimension: a literature review. J Prosthet Dent 1988; 59: 321-323.

26. Shanahan TEJ. Physiologic vertical dimension and centric relation. J Prosthet Dent 1956; 6: 741-747.

27. Klein IE. Complete denture prosthesis: clinical review of accepted procedures. J Prosthet Dent 1973; 30 (4 Pt 2): 622-628.

28. Watarai Y, Mizuhashi F, Sato T, Koide K. Highly producible method for determination of occlusal vertical dimension: relationship between measurement of lip contact position with the closed mouth and area of upper prolabium. J Prosthodont Res 2018; 62: 485-489.

29. Helal MA, Hassan AH. Evaluation of lower facial heights as related to different anthropometric measurements in dentate and completely edentulous subjects. Quintessence Int 2016; 47: 51-60.

30. Sakar O, Sülün T, Kurt H, Gençel B. Reliability and comparison of two facial measurements to detect changes of occlusal vertical dimension in complete denture wearers. Gerodontology 2011; 28: 205-208.

31. Geerts GA, Stuhlinger ME, Nel DG. A comparison of the accuracy of two methods used by pre-doctoral students to measure vertical dimension. J Prosthet Dent 2004; 91: 59-66.

32. Carossa S, Catapano S, Scotti R, Preti G. The unreliability of facia measurements in the determination of the vertical dimension of occlusion in edentulous patients. J Oral Rehabil 1990; 17: 287-290.

33. Gross MD, Nissan J, Ormianer Z, Dvori S, Shifman A. The effect of increasing occlusal vertical dimension on face height. Int J Prosthodont 2002; 15: 353-357.

34. Tryde G, McMillan DR, Christensen J, Brill N. The fallacy of facial measurements of occlusal height in edentulous subjects. J Oral Rehabil 1976; 3: 353-358.

35. Makzoume JE. A procedure for directly measuring the physiologic rest position and occlusal vertical dimension. J Prosthet Dent 2017; 117: 697-698.

36. Morikawa M, Kozono Y, Noguchi BS, Toyoda S. Reproducibility of the vertical dimension of occlusion with an improved measuring gauge. J Prosthet Dent 1988; 60: 58-61.

37. Mohamed SE, Christensen LV. Mandibular reference positions J Oral Rehabil 1985; 12: 355-367.

38. Millet C, Jeannin C, Vincent B, Malquarti G. Report on the determination of occlusal vertical dimension and centric relation using swallowing in edentulous patients. J Oral Rehabil 2003; 30: 1118-1122.

39. Fenlon MR, Sherriff M, Walter JD. Association between the accuracy of intermaxillary relations and complete denture usage. J Prosthet Dent 1999; 81: 520-525.

40. Massad JJ, Connelly ME, Rudd KD, Cagna DR. Occlusal device for diagnostic evaluation of maxillomandibular relationships in edentulous patients: a clinical technique. J Prosthet Dent 2004; 91: 586-590.

41. Tingey EM, Buschang PH, Throckmorton GS. Mandibular rest position: a reliable position influenced by head support and body posture. Am J Orthod Dentofacial Orthop 2001; 120: 614-622.

42. Wright SM. The effect of body posture on the preferred vertical dimension of occlusion. J Oral Rehabil 1984; 11: 467-476.

43. Hellsing G. Functional adaptation to changes in vertical dimension. J Prosthet Dent 1984; 52: 867-870.

44. Williamson EH, Woelfel JB, Williams BH. A longitudinal study of rest position and centric occlusion. Angle Orthod 1975; 45: $130-136$.

45. Montero J, Dib A. The effect of age and prosthodontic status on the clinical and electromyographic assessment of the interocclusal rest space. J Prosthet Dent 2019; 121: 791-796.

46. Montero J, Dib A. The effect of age and prosthodontic status on the clinical and electromyographic assessment of the interocclusal rest space. J Prosthet Dent 2019; 121: 791-796.

47. Lyons MF. An electromyographic study of masticatory muscle activity at increased occlusal vertical dimension in complete denture wearers. J Prosthet Dent 1988; 60: 346-348.

48. van Niekerk FW, Bibby RE, Miller VJ. Relations between edentulous rest position and complete denture intercuspal position. J Prosthet Dent 1984; 52: 406-407.

49. Richardson A, Allen R. Mandibular posture following tooth extraction. J Dent 1980; 8: 315-320.

50. Lambadakis J, Karkazis HC. Changes in the mandibular rest position after removal of remaining teeth and insertion of complete dentures. J Prosthet Dent 1992; 68: 74-77.

51. Ismail YH, George WA, Sassouni V, Scott RH. Cephalometric study of the changes occurring in the face height following prosthetic treatment. Part I. Gradual reduction of both occlusal and rest face heights. J Prosthet Dent 1968; 19: 321-330.

52. Koller MM, Merlini L, Spandre G, Palla S. A comparative study of two methods for the orientation of the occlusal plane and the determination of the vertical dimension of occlusion in edentulous patients. J Oral Rehabil 1992; 19: 413-425.

53. Burnett CA. Clinical rest and closest speech positions in the determination of occlusal vertical dimension. J Oral Rehabil 2000; 27: 714-719.

54. Swerdlow H. Vertical dimension literature review. J Prosthet Dent 1965; 15: 241-247.

55. Atwood DA. A critique of research of the rest position of the mandible. J Prosthet Dent 1966; 16: 848-854.

56. Mohindra NK. A preliminary report on the determination of the vertical dimension of occlusion using the principle of the mandibular position in swallowing. Br Dent J 1996; 180: 344-348.

57. Ekfeldt A, Jemt T, Månsson L. Interocclusal distance measurement comparing chin and tooth reference points. J Prosthet Dent 1982; 47: 560-563.

58. Orthlieb JD, Laurent M, Laplanche O. Cephalometric estimation of vertical dimension of occlusion. J Oral Rehabil 2000; 27: 802-807.

59. Gattozzi JG, Nicol BR, Somes GW, Ellinger CW. Variations in mandibular rest positions with and without dentures in place. J Prosthet Dent 1976; 36: 159-163.

60. Rivera-Morales WC, Mohl ND. Relationship of occlusal vertical dimension to the health of the masticatory system. J Prosthet Dent 1991; 65: 547-553.

61. Kleinman AM, Sheppard IM. Mandibular rest levels with and without dentures in place in edentulous and complete denture-wearing subjects. J Prosthet Dent 1972; 28: 478-484.

62. Silverman SI. Vertical dimension record: a three dimensional phenomenon. Part II. J Prosthet Dent 1985; 53: 573-577. 
63. Sheppard IM, Sheppard SM. Vertical dimension measurements. J Prosthet Dent 1975; 34: 269-277.

64. Obrez A, Türp JC. The effect of musculoskeletal facial pain on registration of maxillomandibular relationships and treatment planning: a synthesis of the literature. J Prosthet Dent 1998; 79 439-445.

65. Silverman MM. The speaking method in measuring vertical dimension. 1952. J Prosthet Dent 2001; 85: 427-431.

66. Burnett CA, Clifford TJ. Closest speaking space during the production of sibilant sounds and its value in establishing the vertical dimension of occlusion. J Dent Res 1993; 72: 964-967.

67. de Souza RF, Marra J, Pero AC, Compagnoni MA. Effect of denture fabrication and wear on closest speaking space and interocclusa distance during deglutition. J Prosthet Dent 2007; 97: 381-388.

68. Pound E. Controlling anomalies of vertical dimension and speech J Prosthet Dent 1976; 36: 124-135.

69. Murrell GA. Phonetics, function, and anterior occlusion. J Prosthet Dent $1974 ; 32: 23-31$.

70. Negucioiu M, Popa D, Juncar R, Juncar M. The minimum phonetic dimension in total edentulous patients: a different method for determining the vertical dimension of occlusion. HVM Bioflux 2017; 9: 28-32.

71. Rivera-Morales WC, Mohl ND. Variability of closest speaking space compared with interocclusal distance in dentulous subjects. J Prosthet Dent 1991; 65: 228-232.

72. George JP. Using the Kinesiograph to measure mandibular movements during speech: a pilot study. J Prosthet Dent 1983; 49: 263-270.

73. Shanahan TEJ. Physiologic jaw relations and occlusion of complete dentures. 1955. J Prosthet Dent 2004; 91: 203-205.

74. Čimić S, Šimunković SK, Gospić RK, Badel T, Dulčić N, Ćatić A. Movements of temporomandibular condyles during swallowing. Coll Antropol 2015; 39: 159-164.

75. Abdel-Hakim AM. The swallowing position as a centric relation record. J Prosthet Dent 1982; 47: 12-15.

76. Ismail YH, George WA. The consistency of the swallowing technique in determining occlusal vertical relation in edentulous patients. J Prosthet Dent 1968; 19: 230-236.

77. Yamashita S, Shimizu M, Katada H. A newly proposed method to predict optimum occlusal vertical dimension. J Prosthodont 2015; 24: 287-290.

78. Chou TM, Moore DJ, Young L Jr, Glaros AG. A diagnostic craniometric method for determining occlusal vertical dimension. J Prosthet Dent 1994; 71: 568-574.

79. Brzoza D, Barrera N, Contasti G, Hernández A. Predicting vertical dimension with cephalograms, for edentulous patients. Gerodontology 2005; 22: 98-103.

80. Sudhir N, Chittaranjan B, Kumar BA, Taruna M, Kumar MP, Red dy MR. Digital cephalometric tracings by PRO-CEPH V3 software for comparative analyses of vertical dimension in edentulous patients. J Clin Diagn Res 2015; 9: ZC01-5.

81. Hull CA, Junghans JA. A cephalometric approach to establishing the facial vertical dimension. J Prosthet Dent 1968; 20: 37-42.

82. Enkling N, Enkling-Scholl J, Albrecht D, Bornstein MM, Schimmel M. Determination of the occlusal vertical dimension in edentulous patients using lateral cephalograms. J Oral Rehabil 2018 45: 399-405.

83. Bissasu M. Pre-extraction records for complete denture fabrication: a literature review. J Prosthet Dent 2004; 91: 55-58.

84. Smith DE. The reliability of pre-extraction records for complete dentures. J Prosthet Dent 1971; 25: 592-608.

85. Merkeley HJ. A complete standardized pre-extraction record J Prosthet Dent 1953; 3: 657-659.

86. Turner LC. The profile tracer: method for obtaining accurate pre-extraction records. J Prosthet Dent 1969; 21: 364-370.

87. Timmer $\mathrm{LH}$. A reproducible method for determining the vertical dimension of occlusion. J Prosthet Dent 1969; 22: 621-630.

88. Lytle RB. Vertical relation of occlusion by the patient's neuromuscular perception. J Prosthet Dent 1964; 14: 12-21.
89. Wojdyla SM, Wiederhold DM. Using intraoral Gothic arch tracing to balance full dentures and determine centric relation and occlusal vertical dimension. Dent Today 2005; 24: 74-77.

90. Bissasu M. Use of a patient's old complete denture to determine vertical dimension of occlusion. J Prosthet Dent 2001; 85: 413-414.

91. Morata C, Pizarro A, Gonzalez H, Frugone-Zambra R. A craniometry-based predictive model to determine occlusal vertical dimension. J Prosthet Dent 2020; 123: 611-617.

92. Douglas JR, Maritato FR. "Open rest," a new concept in the selection of the vertical dimension of occlusion. J Prosthet Dent 1965 15: 850-856.

93. Pitigoi-Aron G, Labarre E, Giusti L, Leknius C. Fabrication of a caliper device for interalveolar dimension measurement in the complete denture patient. J Prosthodont 2008; 17: 508-510.

94. Yanikoğlu ND, Güldağ MU, Duymuş ZY. Determination of the occlusal vertical dimension: use of maxillary and mandibular posterior teeth measurement in edentate subjects. Eur J Prosthodont Restor Dent 2005; 13: 75-77.

95. Sihuay-Torres K, Castro-Rodriguez Y. Relationship between the occlusal vertical dimension and anthropometric measurements of the fingers. J Oral Res 2019; 8: 282-289.

96. Bhandari Aruna J, Ladda R, Bhandari Akshay J. Correlation between vertical dimension of occlusion and length of little finger. Pravara Med Rev 2012; 4: 10-14.

97. Michman J, Langer A. Comparison of three methods of registering centric relation for edentulous patients. J Prosthet Dent 1963; 13: 248-254.

98. Helft M, Cardash H, Kaufman C. Combining final impressions with maxillomandibular relation records in stabilized record bases. J Prosthet Dent 1978; 39: 135-138.

99. Ismail YH, Rokni A. Radiographic study of condylar position in centric relation and centric occlusion. J Prosthet Dent 1980; 43 327-330.

100. Yurkstas AA, Kapur KK. Factors influencing centric relation records in edentulous mouths. 1964. J Prosthet Dent 2005; 93: 305-310.

101. Myers ML. Centric relation records-historical review. J Prosthet Dent 1982; 47: 141-145.

102. Thakur M, Jain V, Parkash H, Kumar P. A comparative evaluation of static and functional methods for recording centric relation and condylar guidance: a clinical study. J Indian Prosthodont Soc 2012; 12: 175-181.

103. Myers M, Dziejma R, Goldberg J, Ross R, Sharry J. Relation of Gothic arch apex to dentist-assisted centric relation. J Prosthet Dent 1980; 44: 78-81.

104. ARCUSdigma. Instructions for Use. https://embed.widencdn.net/download/kavokerr/etqwlabi3u/GA_ARCUSdigmaII_20080619_01_en.pdf?u=a0aubk (Accessed: 20.04.2021).

105. Jacob RF. The traditional therapeutic paradigm: complete denture therapy. J Prosthet Dent 1998; 79: 6-13.

106. Akerly WB. Recording jaw relationships in edentulous patients. Dent Clin North Am 1996; 40: 53-70.

107. Douglass JB, Meader L, Kaplan A, Ellinger CW. Cephalometric evaluation of the changes in patients wearing complete dentures: a 20-year study. J Prosthet Dent 1993; 69: 270-275.

108. Sofou AM, Diakoyianni-Mordohai I, Emmanouel I, Markovitsi H, Pissiotis AL. Using cephalometry to evaluate maxillomandibular relationships in complete denture construction. Int J Prosthodont 1993; 6: 540-545.

109. Bissasu M. Use of the tongue for recording centric relation for edentulous patients. J Prosthet Dent 1999; 82: 369-370.

110. Nasr MF, Griffiths NH. Exercise therapy for accurate recording of centric relation. J Prosthet Dent 1973; 29: 5-9.

111. Boulos PJ. Simplified method for recording maxillomandibular relations in complete dentures. N Y State Dent J 2007; 73: 24-27. 